\title{
Langmuir-Schaefer films of regioregular polythiophene derivatives as VOCs sensors
}

\author{
Vinicius J.R. Oliveira, L.V.L. Citolino, S.A. Camacho, P. Alessio, C.A. Olivati* \\ Faculdade de Ciências e Tecnologia, UNESP, Presidente Prudente, SP, 19060-900, Brazil
}

\section{H I G H L I G H T S}

- The P3HT and P3OT polymers were scattered on a water-air surface of a Langmuir trough.

- Through isotherms ( $\pi-\mathrm{A})$ one can identify the organization phases of the molecules.

- The thin films presented linear growth through of Langmuir Schaefer technique.

- The thin films on the interdigitated electrode quickly detected the organic vapor.

- Raman mapping detected the physical interactions between organic polymers and vapors.

\section{A R T I C L E I N F O}

\section{Keywords:}

Polythiophene

Langmuir-Schaefer

VOCs sensors

Spectroscopy measurements
G R A P H I C A L A B S T R A C T

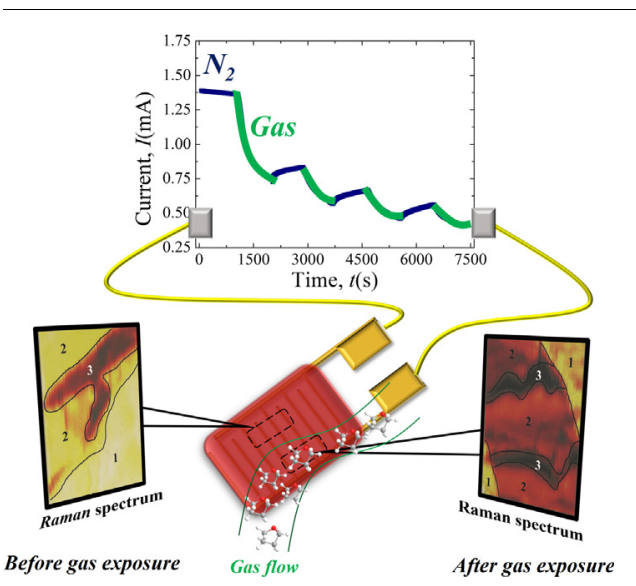

\begin{abstract}
A B S T R A C T
Conjugated polymers have been extensively studied in recent years, with high technological potential for application as an active layer of organic devices. In this context, polythiophene derivatives have attracted attention due to properties as stability and easy processability. In this work, poly(3-hexylthiophene) and poly(3-octylthiophene) were studied in the form of nanostructured films fabricated by the Langmuir-Schaefer deposition technique. The films were characterized by optical (UV-Vis absorption spectroscopy and Raman scattering) and electrical measurements allowing the evaluation of the material concerning the technological potential to the manufacture of VOCs electric sensors.
\end{abstract}

\section{Introduction}

Conductive polymers have remarkable properties in the solid state, such as high processability and stability. They have been used in the form of thin films with wide application in organic electronic devices as OLEDs, photovoltaic [1-5]. These organic devices are frequently based on thin films [6]. Therefore, the Langmuir-Schaefer (LS) technique is known to provide nanostructured films with the great organization at the molecular level and control in the thickness and uniformity. Thus, the LS technique is suitable for the manufacture of sensors based the polymeric thin films $[7,8]$.

In another way, concern about possible damages caused by volatile organic compounds (VOCs) in the atmosphere has increased, encouraging research on systems for the detection of these harmful compounds in the air $[9,10]$.

\footnotetext{
* Corresponding author.

E-mail addresses: vinijro@gmail.com (V.J.R. Oliveira), lucasvinicius_blink@hotmail.com (L.V.L. Citolino), sabrina.alessio@gmail.com (S.A. Camacho), priscila@fct.unesp.br (P. Alessio), olivati@fct.unesp.br (C.A. Olivati).
} 
For instance, dichloromethane is a colorless and highly volatile substance, as well as tetrahydrofuran; characteristics make them almost imperceptible in the atmosphere. However, these VOCs can be found in home environments, in products such as aerosols, pesticides, spray paints, or resin solvents. In fact, breathing large amounts of dichloromethane leads to symptoms such as dizziness, nausea, numbness in the fingers, or in more severe cases result in respiratory and cardiac insufficiency [11]. The Tetrahydrofuran produces similar symptoms, in addition to respiratory tract irritation and headaches, besides being considered a carcinogenic agent to humans [12].

Thus, the main idea is to control these substances in the atmosphere, developing alternative portable sensors with low cost facilitates the popularization, resulting in greater health conditions to the environments [13]. In this sense, sensors based on conductive organic polymers, for example, regioregular polythiophenes, as the active layer are an interesting alternative device.

The conventional detectors available in the market, such as Hydrogen detectors, fuel gasses, and solvents, has a cost of sale of almost US \$ 1000 [14]. In contrast, companies such as ABTECH Scientific, Inc. Advanced Biochip Technologies, produce sensors based on organic conducting polymers with a maximum price of US \$ 230 [15].

Sensors based on organic chemosensing polymers interact with the analyte of interest that changes their optical, chemical or electrical properties [16]. The changes can be detected and translated into a response of the sensor to the interaction of the sensor with the analytes [4,17].

In this work, the polythiophene regioregular derivatives, Poly(3hexylthiophene) (P3HT) and Poly (3-octylthiophene) (P3OT), were processed through the Langmuir-Schaefer (LS) technique, and characterized by optical (UV-Vis absorption spectroscopy and Raman scattering) and electrical measurements (direct current - DC). The results reveal the device manufactured has technological potential to the application as VOCs electric sensor.

\section{Materials and methods}

\subsection{Materials}

The regioregular derivatives of polythiophene, poly(3-hexylthiophene) (P3HT, $\left(\mathrm{C}_{10} \mathrm{H}_{14} \mathrm{~S}\right)_{\mathrm{n}}$ ) and poly(3-octylthiophene) (P3OT, $\left.\left(\mathrm{C}_{12} \mathrm{H}_{18} \mathrm{~S}\right)_{\mathrm{n}}\right)$, were acquired from Sigma-Aldrich (product numbers: 445703 and 445711 , respectively, regiospecific $\geq 90 \%$ ). The solvents used for measures as sensors of volatile organic compounds (VOCs) were dichloromethane $\left(\mathrm{CH}_{2} \mathrm{Cl}_{2}, \quad \mathrm{MW}=84.93 \mathrm{~g} / \mathrm{mol}\right)$ and tetrahydrofuran $\left(\mathrm{C}_{4} \mathrm{H}_{8} \mathrm{O}\right.$, MW $\left.=72.11 \mathrm{~g} / \mathrm{mol}\right)$ also purchased from SigmaAldrich. The ultrapure water $(18.2 \mathrm{M} \Omega \mathrm{cm})$ was acquired from a Millipore system of water purification.

\subsection{Langmuir and Langmuir-Schaefer films of P3HT and P3OT}

Langmuir and Langmuir-Schaefer (LS) films of P3HT and P3OT were fabricated using a Langmuir trough KSV-NIMA model 5000. Langmuir films were produced by spreading $600 \mu \mathrm{L}$ of P3HT and P3OT solutions $(0.20 \mathrm{mg} / \mathrm{mL}$ dissolved in chloroform) onto air/water interface. The Langmuir monolayers were characterized by $\pi-\mathrm{A}$ isotherms at $23^{\circ} \mathrm{C}$ using the Wilhelmy method. The monolayers were symmetrically compressed under a constant barrier speed at $10 \mathrm{~mm} / \mathrm{min}$ with the subphase containing ultrapure water. LS films of P3HT and P3OT were obtained by transferring the Langmuir monolayers from the air/water interface onto different solid substrates depending on the characterization technique: quartz substrates (13 layers) for UV-Vis absorption and Raman spectroscopy) and interdigitated gold electrodes (IDE) (25 layers) for electrical characterization and sensor measures. The interdigitated gold electrodes (IDEs) were fabricated using glass as a substrate by the technique of photolithography. The depositions were carried out approaching manually and horizontally the substrates to the air/water interface at a constant surface pressure of $20 \mathrm{mN} / \mathrm{m}$.

\subsubsection{Films characterization}

The UV-Vis absorption spectroscopy characterization of P3HT and P3OT solutions $(0.2 \mathrm{mg} / \mathrm{mL}$, chloroform solution) and LS films were performed using a Varian spectrophotometer, model Cary 100, from 400 to $800 \mathrm{~nm}$. The growth of P3HT and P3OT LS films deposited onto quartz substrates was monitored every 2 layers up to 13 layers.

Raman analysis of P3HT and P3OT LS films were performed before and after THF gas exposure. For that, the LB films were exposed to THF gas atmosphere for $30 \mathrm{~min}$ and then brought to Raman analysis. Raman spectra and morphological features (at micrometer scale) of P3HT and P3OT LS films (before and after gas exposure) were investigated using a Renishaw in-Via micro-Raman system equipped with a Leica microscope. A $50 \times$ microscope objective long lens allows collecting the spectra with ca. $1 \mu \mathrm{m}^{2}$ spatial resolution, a CCD detection, and a computer-controlled three-axis-encoded (XYZ) motorized stage to allow Raman spectra to be recorded with a minimum step of $0.1 \mu \mathrm{m}$. Raman spectra and Raman mapping were carried out with the laser line at $633 \mathrm{~nm}, 1800$ grooves/mm gratings and edge filters.

Electrical characterizations of LS films of P3HT and P3OT, deposited onto IDE, was performed by current $v s$. voltage measurements $(I-V)$, using a source of voltage Keysight, model B2901A.

\subsection{VOCs sensor measures}

Electrical characterization of sensors built using LS films of P3HT and P3OT deposited onto IDE was carried out by alternating periods of exposure to continuous flow between, volatile organic compounds and nitrogen flow. The volatile organic compounds dichloromethane and tetrahydrofuran were used in the current versus time $(I-t)$ measurements by applying a constant voltage of $5 \mathrm{~V}$. The sensors (LS films of $\mathrm{P} 3 \mathrm{HT}$ and P3OT) were submitted to the measures in a system containing a constant gas flow of $60 \mathrm{NL} / \mathrm{h}$, where NL is a mass unit for gasses equal to the mass of $1 \mathrm{~L}$, under a pressure of $1 \mathrm{~atm}$ at standard temperature. This flow value is kept during all measurement period, which may be accompanied by a flow meter. First of all, nitrogen flow is applied for $30 \mathrm{~min}$, to establish a baseline with this inert gas. After that, the nitrogen is released to drag the volatile organic compound to the sensor for $15 \mathrm{~min}$, and then, more $15 \mathrm{~min}$ back to the nitrogen flow to return to the baseline. The process of alternating cycles between nitrogen flow and the organic solvent is repeated until a standard behavior of the sensor's electrical signal is observed when in contact with the volatile organic compound. The schematic representation of the electrical measurements setup for VOCs sensors is shown in Fig. 1.

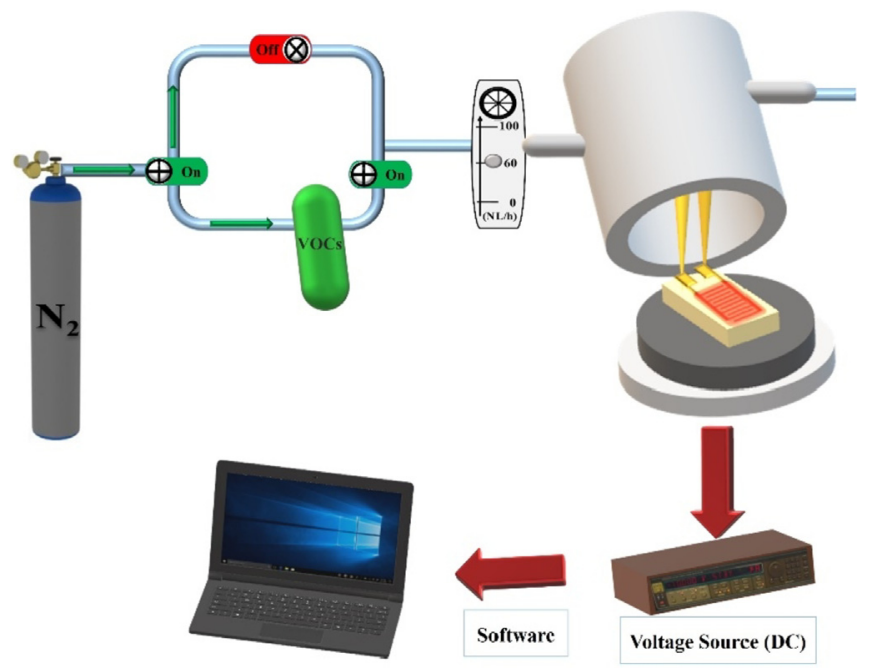

Fig. 1. Schematic representation of the system for electrical conductivity and gas flow measurements. 


\section{Results and discussion}

\subsection{Langmuir films of P3OT and P3HT}

The $\pi$-A isotherms of P3HT and P3OT Langmuir films are displayed in Fig. 2a and b, respectively. The occupied area per P3HT and P3OT molecules are estimated to be ca. $6.7 \AA^{2}$ and $5.2 \AA^{2}$, respectively, by extrapolating the linear region of the isotherms, at the phase condensed $(20 \mathrm{mN} / \mathrm{m})$, to zero pressures. These values agree with those found in isotherms of the alkyl-substituted polythiophene derivative (P3AT). According to the authors [18], the low values of occupied area per molecule of these polythiophenes are associated with the angle between the aromatic ring (from P3HT and P3OT molecules) and the aqueous subphase at the Langmuir trough. Also, it is observed that the number of carbons in the lateral chain of these polythiophenes affects the surface pressure of the collapse region. For instance, the P3HT, which has the lower number of carbons in the lateral chain, exhibits the higher surface pressure at the collapse region, while the P3OT, containing the higher number of carbons in the lateral chain, shows the lower surface pressure at the collapse region.

The rigidity of these regioregular polymers [19] forming Langmuir films at the interface air/water allows the deposition on solid substrates at a surface pressure of $20 \mathrm{mN} / \mathrm{m}$, fabricating Langmuir-Schaefer (LS) films [20].

\subsection{P3OT and P3HT LS films growth}

The growth of P3HT and P3OT LS films monitored by UV-Vis absorption spectroscopy are presented in Fig. 3a and b, respectively, where the UV-Vis spectra were recorded every 2 layers up to 13 layers. The insets in Fig. 3a and b shows the absorbance at $520 \mathrm{~nm}$ and $524 \mathrm{~nm}$ for different numbers of deposited layers for P3HT and P3OT LS films, respectively. The linear growth of absorbance indicates that similar amounts of polythiophene derivates are transferred per deposited layer, revealing a controlled growth of the LS films. The three adsorption bands observed in the P3HT LS film (13 layers) at 520, 551 and $598 \mathrm{~nm}$,
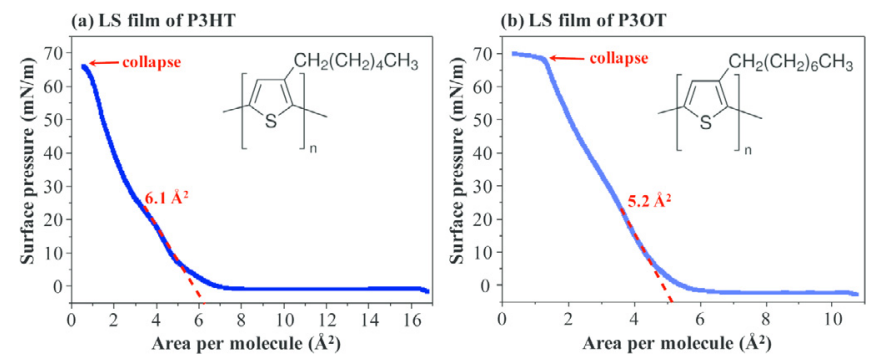

Fig. 2. $\pi$-A isotherms of (a) P3HT and (b) P3OT recorded for the ultrapure water subphase at room temperature $\left(23^{\circ} \mathrm{C}\right)$. The occupied area per molecules and the collapse regions are highlighted on the isotherms.
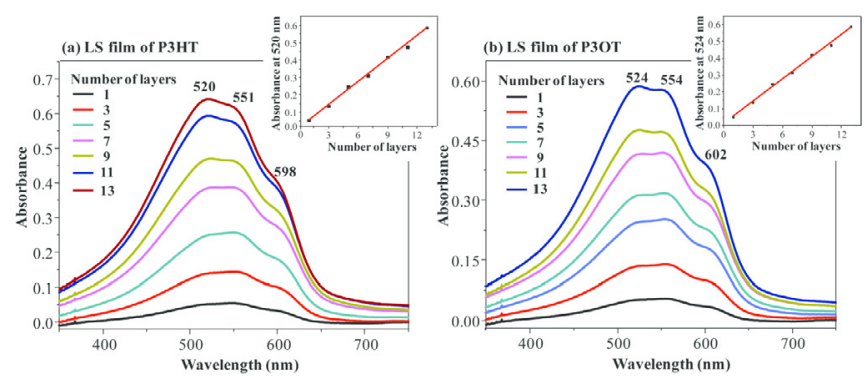

Fig. 3. UV-Vis absorption for LS films of (a) P3HT and (b) P3OT. The insets show the absorbance at $520 \mathrm{~nm}$ and $524 \mathrm{~nm}$ of P3HT and P3OT LS films for different numbers of layers.
Table 1

Parameters associated with the molecular ordering and charge carrier mobility for the LS films of P3HT and P3OT.

\begin{tabular}{llllll}
\hline LS Film & $\begin{array}{l}\text { Number of } \\
\text { layers }\end{array}$ & $\begin{array}{l}\lambda_{\mathrm{AO}-0} \\
(\mathrm{~nm})\end{array}$ & $\begin{array}{l}\mathrm{A}_{0-0} \text { (arb. } \\
\text { unit.) }\end{array}$ & $\begin{array}{l}\mathrm{A}_{0-1} \text { (arb. } \\
\text { unit.) }\end{array}$ & $\mathrm{A}_{0-0} / \mathrm{A}_{0-1}$ \\
\hline P3HT & 1 layer & 596 & 0.034 & 0.055 & 0.62 \\
& 13 layers & 598 & 0.409 & 0.616 & 0.66 \\
P3OT & 1 layer & 602 & 0.032 & 0.054 & 0.60 \\
& 13 layers & 602 & 0.388 & 0.575 & 0.67 \\
\hline
\end{tabular}

and in the P3OT LS film (13 layers) at 524, 554 and $602 \mathrm{~nm}$, are assigned to vibronic peaks $\mathrm{A}_{0-2}, \mathrm{~A}_{0-1}$, and $\mathrm{A}_{0-0}$, respectively [21,22]. The first two bands $\left(\mathrm{A}_{0-2}\right.$ and $\left.\mathrm{A}_{0-1}\right)$ have contributions from an intrachain exciton [23], while the lowest energy band $\left(\mathrm{A}_{0-0}\right)$ is attributed to interchain adsorption of the regioregular polythiophenes [24], characteristic of conjugated polymers, which are associated with $\pi-\pi^{*}$ transition [25,26] from carbon atoms linked by double bonds in the aromatic ring of the polythiophenes structures [27,28]. The intensity and the red-shift of the vibronic transition $\mathrm{A}_{0-0}$, at $\sim 600 \mathrm{~nm}$, are related with the ordering degree of the P3HT and P3OT chains [29], while the intensity of the amplitude ratio $\left(\mathrm{A}_{0-0} / \mathrm{A}_{0-1}\right)$ is associated with the charge carrier mobility [24,30]. For a better understanding of how the molecular ordering and charge carrier mobility of the LS films changes throughout the depositions the parameters mentioned above are depicted for 1 and 13 layers of each LS film in Table 1.

The red-shift and the relative increase of absorption intensity of the band $\mathrm{A}_{0-0}$, noticed for the LS film of P3HT (from 1 to 13 layers), indicates an increase in the molecular ordering of this film [29]. Besides, the band $\mathrm{A}_{0-0}$ becomes more pronounced as the layers are deposited, which is another indication of the higher molecular ordering for the LS film of P3HT 13 layers [31]. When compared the amplitude ratio $\left(\mathrm{A}_{0-0}\right)$ $\mathrm{A}_{0-1}$ ) of the LS film of P3HT 13 layers with that of 1 layer, a higher value is found for the 13 layers, which favors the charge mobility of this film [31].

Similar behavior is observed for the LS film of P3OT (from 1 to 13 layers). Although a red-shift of the band $\mathrm{A}_{0-0}$ is not noticed, the relative increase of absorption intensity indicates an increase in the molecular ordering, from 1 to 13 layers [29]. Also, the increase in the amplitude ratio $\left(\mathrm{A}_{0-0} / \mathrm{A}_{0-1}\right)$ for this film (from 1 to 13 layers) is higher than for the LS film of P3HT (from 1 to 13 layers). The latter suggests the charge carrier mobility increases more for the deposition of the LS film of P3OT than P3HT [31].

\subsection{DC electrical characterization}

The DC conductivity measurements were performed on an interdigitated chromium-gold array for P3HT and P3OT LS films. From linear fit of $I$ vs. $V$ curves (Fig. 4), it is possible to estimate the conductivity $(\sigma)$ and the resistance (R) of the material using Equation (1), the parameters presented in detail elsewhere [32].

$\sigma=\frac{1}{R} \frac{L}{A}=\frac{1}{R}(k)$.

where, the electrical conductivity is calculated from the linear adjustment of the presented experimental curve, and since the slope of the line is the inverse of $\mathrm{R}$ (in $\Omega$ ), the electrical conductivity $\sigma(\mathrm{S} / \mathrm{m}$ ) is the inverse of the resistivity $\rho$, which can be determined by relating $\mathrm{L}$ as conductor length and A (cross-sectional area in $\mathrm{m}$ ). Thus, the electrical conductivity $\sigma$ can be obtained through the model of Olthuis et al. [32], and inserting the cell constant value $\mathrm{K}=5.1 \mathrm{~m}^{-1}$. The constant $\mathrm{K}$ is equivalent to constant ratio $\mathrm{L} / \mathrm{A}$, obtained through the geometry of the conductor and considerer the spacing, height, and length of digits of the IDE used. The conductivity value measured in the dark was in the order of $10^{-6} \mathrm{~S} / \mathrm{m}$, which is in agreement with the values of neutral 


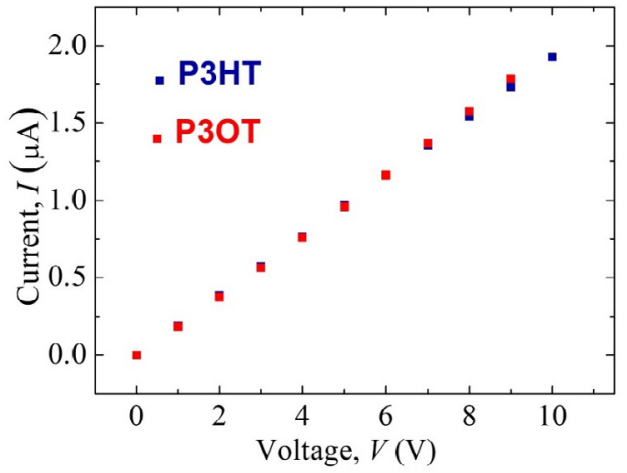

Fig. 4. DC electrical characterization ( $I$ vs. $V$ ) for the P3HT and P3OT films deposited by Langmuir-Schaefer technique onto gold IDE.

regioregular polythiophenes [18].

Figs. 5 and 6 show the electrical responses of the sensors upon the exposures to different VOCs. It was observed a negative and fast response in all cases, indicating that the conductivity of the materials is decreasing in the presence of the gases [33]. For P3HT/P3OT dichloromethane sensors the current values return to initial ones showing that the devices are reversible [34]. On the other hand, when the microsensors were exposed to THF, it was observed that the current did not return to the initial value being partially reversible.

The negative electrical response of the sensor can be explained since the organic VOCs used are solvents of the polythiophenes, where the passage of this vapor on the polymer sample in the form of a thin film can alter the conformation of its chains. This effect caused by swelling of the LS films can increase the distance between the chains. Since the transport mechanism in these materials is due to polaron hopping conduction, the swelling effects cause a decrease in the electrical conductivity $[4,35]$. This swelling effect depends on the polymer-vapor interactions and the polymer solubility. The partial reversibility for THF sensors probably is due to the higher degree of solubility of this compound when compared to dichloromethane [36,37].

The P3HT and P3OT sensors show a rapid response to gas exposure. In the presence of dichloromethane, the sensors present a response
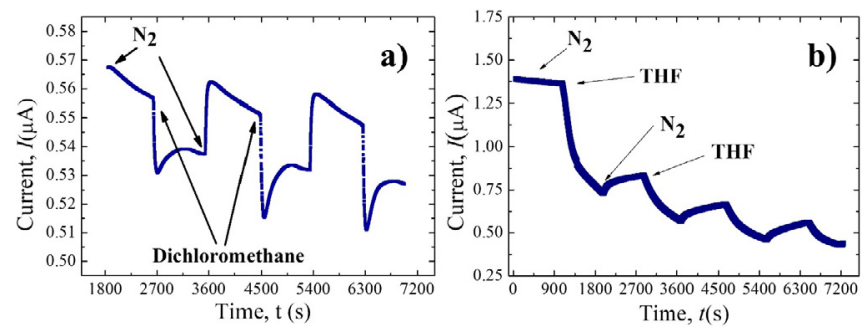

Fig. 5. Measures ( $\mathrm{x}$ t) with the LS film of P3HT in the presence of vapors of (a) dichloromethane and (b) tetrahydrofuran (THF).
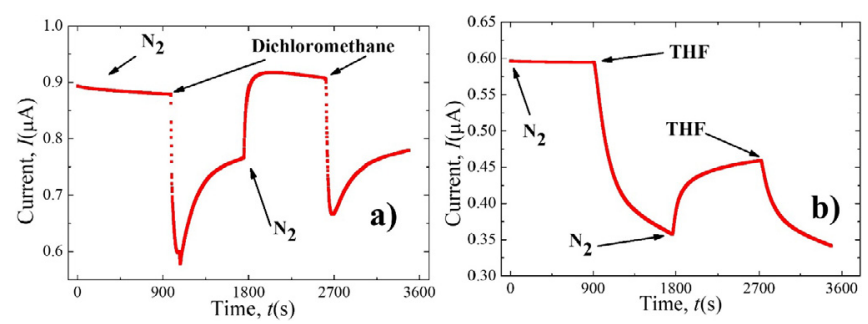

Fig. 6. Measures ( $\mathrm{I} x \mathrm{t}$ ) with the LS film of P3OT in the presence of vapors of (a) dichloromethane and (b) tetrahydrofuran (THF). within the first $3 \mathrm{~s}$ with an abrupt change of the electrical current. After exposure of the sample in nitrogen flow, the devices exhibited total recovery in approximately $3 \mathrm{~min}$.

While in the presence of THF, the response time is around $5 \mathrm{~min}$ and a return to a certain level of stabilization shortly after $13 \mathrm{~min}$ of exposure in an inert atmosphere. The response and recovery times of the samples studied are in the same range to the recovery and detection time of organic vapors reported in the literature for polythiophene derivatives detecting volatile organic compounds [38-40].

\subsection{Morphology of P3HT and P3OT LS films before and after gas exposure}

The spatial distribution of the P3HT and P3OT in the LS films were evaluated, at the micrometer scale, using the micro-Raman technique, which combines morphological and chemical information by coupling an optical microscope to a Raman spectrograph. Fig. 7 shows point-bypoint area Raman mappings superimposed to optical images of the P3HT and P3OT LS films before and after THF gas exposure. The Raman mappings were obtained recording spectra from areas of $100 \mu \mathrm{m} \times 70 \mu \mathrm{m}$ with $1 \mu \mathrm{m}$ of step (three of them are shown in Fig. $7 \mathrm{a}$, $\mathrm{b}, \mathrm{c}$, and d), where brighter spots indicate the higher relative intensity of the band at $1445 \mathrm{~cm}^{-1}$, assigned to symmetric $\mathrm{C}=\mathrm{C}$ stretching $[23,41]$. The others two bands around 1381 and $728 \mathrm{~cm}^{-1}$ are attributed to $\mathrm{C}-\mathrm{C}$ intra-ring stretching and $\mathrm{C}-\mathrm{S}-\mathrm{C}$ ring skeleton deformation, respectively $[23,41,42]$.

To investigate how the THF gas atmosphere affects the morphology of the LS films, the molecular ordering of P3HT and P3OT was analyzed before and after gas exposure. For that, three important parameters were investigated to identify the molecular ordering of these polymers: i) peak position of $\mathrm{C}=\mathrm{C}$ stretching mode $\left(1445 \mathrm{~cm}^{-1}\right)$ shifts to lower wavenumbers; ii) the relative intensity of $\mathrm{C}-\mathrm{C}$ mode $\left(1381 \mathrm{~cm}^{-1}\right)$ to $\mathrm{C}=\mathrm{C}$ mode $\left(1445 \mathrm{~cm}^{-1}\right)\left(\mathrm{I}_{\mathrm{C}-\mathrm{C}} / \mathrm{I}_{\mathrm{C}=\mathrm{C}}\right)$ becomes larger; and iii) full width at half maximum (FWHM) of $\mathrm{C}=\mathrm{C}$ stretching mode $\left(1445 \mathrm{~cm}^{-1}\right)$ becomes narrower $[41,43]$. These three parameters are presented in Table 2 for the LS films of P3HT and P3OT before and after THF gas exposure.
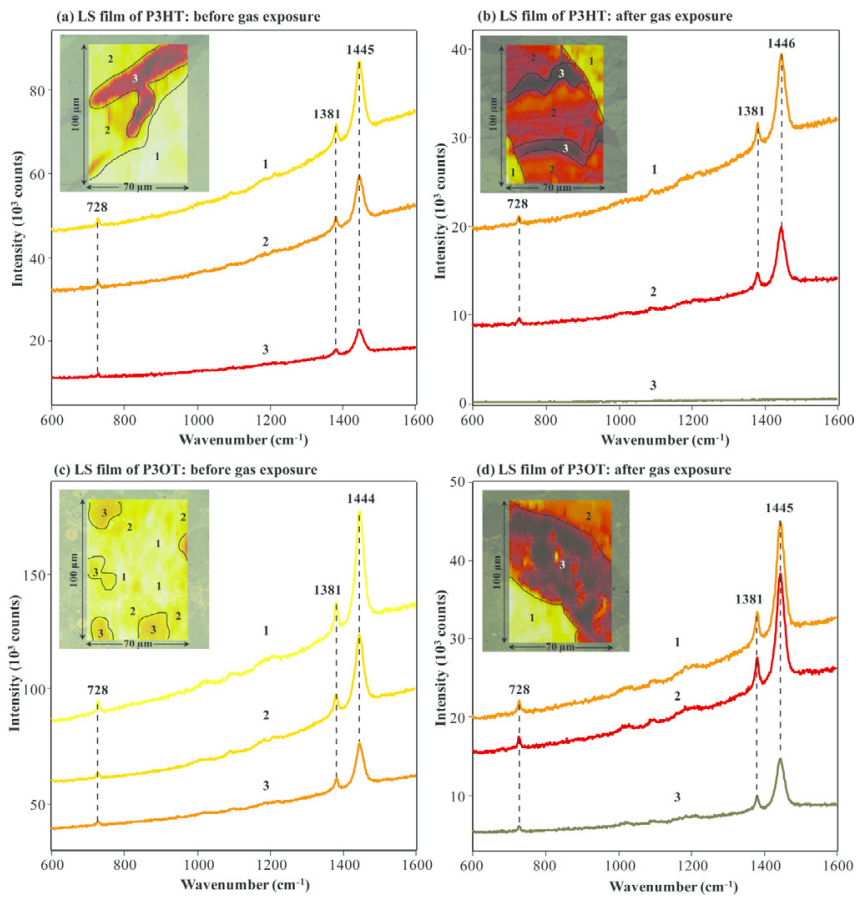

Fig. 7. Raman spectra and area Raman mappings superimposed to optical images of P3HT LS film (a) before and (b) after gas exposure and P3OT LS film (c) before and (d) after gas exposure. 
Table 2

Parameters applied to identify the molecular ordering of the LS films before and after THF gas exposure.

\begin{tabular}{lllll}
\hline & $\begin{array}{l}\text { THF gas exposure } \\
(30 \mathrm{~min})\end{array}$ & $\begin{array}{l}\text { Peak position of } \\
\mathrm{C}=\mathrm{C} \text { mode }\left(\mathrm{cm}^{-1}\right)\end{array}$ & $\mathrm{I}_{\mathrm{C}-\mathrm{C}} / \mathrm{I}_{\mathrm{C}=\mathrm{C}}$ & $\begin{array}{l}\text { FWHM of C=C } \\
\text { mode }\left(\mathrm{cm}^{-1}\right)\end{array}$ \\
\hline \multirow{2}{*}{ P3HT } & Before & 1445 & 0.83 & 25 \\
& After & 1446 & 0.76 & 30 \\
P3OT & Before & 1444 & 0.79 & 25 \\
& After & 1445 & 0.70 & 26 \\
\hline
\end{tabular}

The Raman mappings superimposed to the optical images (insets of Fig. 7) reveal non-homogeneous film surfaces at the microscale, even for the LS films of P3HT and P3OT before THF gas exposure. Although the Raman spectra recorded from distinct spots of the mappings show discrepancies regarding the relative intensities of the band around $1445 \mathrm{~cm}^{-1}$, the relative intensities for the LS films after gas exposure are smaller than before gas exposure. For instance, in the case of P3HT LS film, the relative intensities of the band around $1445 \mathrm{~cm}^{-1}$ after gas exposure (Fig. 7b) are at least two times smaller than before gas exposure (Fig. 7a). Also, Raman spectra recorded from the region 3 (Fig. 7b) come from the substrate (glass Raman signal), indicating that the exposure to THF gas atmosphere affects the morphology of this film physically, forming cracked domains. These results are in agreement with the parameters of molecular ordering of the P3HT and P3OT LS films before and after gas exposure (Table 2). Differences in the values of $\mathrm{I}_{\mathrm{C}-\mathrm{C}} / \mathrm{I}_{\mathrm{C}=\mathrm{C}}$ and FWHM of $\mathrm{C}=\mathrm{C}$ mode found for the LS film of P3HT before and after gas exposure confirm that the morphology of this film was more affected than the LS film of P3OT, resulting in higher molecular disorder [44] which represents a limitation to the carrier mobility in polymer matrices $[45,46]$.

\section{Conclusion}

LS nanostructured films of polythiophene derivatives (P3HT and P3OT) were produced. The films show controlled growth behavior and irregular morphology. Both derivatives were deposited onto solid substrates (IDE), presenting good optical and electrical properties, with reproducible values of electrical conductivity. The VOCs sensors present an electrical response for THF and dichloromethane detection, decreasing the electrical current. Complementary, Raman analysis of P3HT and P3OT LS films before and after THF exposure, confirmed that the morphology of P3HT LS film was more affected than the P3OT LS film, resulting in higher molecular disorder. The Raman mappings revealed the sensing mechanisms involves mainly physical interactions between the polymers and VOCs, forming cracked domains on the LS films after gas exposure. Thus, the device proposed here is promising for use in VOCs sensors.

\section{Acknowledgments}

The authors are grateful for the financial support of the agencies CAPES, FAPESP, INEO/CNPq and CNPEM/LNNano.

\section{References}

[1] S.R. Forrest, The path to ubiquitous and low-cost organic electronic appliances on plastic, Nature 428 (2004) 911-918, http://dx.doi.org/10.1038/nature02498.

[2] A.V.T. Muhammad Yasin, T. Tauqeer, Khasan S. Karimov, Sait E. San, Arif Kösemene, Yusuf Yerli, P3HT: PCBM blend based photo organic field effect transistor, Microelectron. Eng 130 (2014) 13-17, http://dx.doi.org/10.1016/j.mee. 2014.08.010

[3] Z. Bao, A. Dodabalapur, A.J. Lovinger, Z. Bao, A. Dodabalapur, A.J. Lovinger, Soluble and processable regioregular poly(3hexylthiophene) for thin film fieldeffect transistor applications with high mobility, Appl. Phys. Lett. 69 (1996) 4108-4110, http://dx.doi.org/10.1063/1.117834.

[4] H. Bai, G. Shi, Gas sensors based on conducting polymers, Sensors 7 (2007)
267-307

[5] T. Huynh, P.S. Sharma, M. Sosnowska, F.D. Souza, W. Kutner, Functionalized polythiophenes: recognition materials for chemosensors and biosensors with superior sensitivity, selectivity, and detectability, Prog. Polym. Sci. 47 (2015) 1-25, http://dx.doi.org/10.1016/j.progpolymsci.2015.04.009.

[6] M. Eslamian, Inorganic and organic solution-processed thin film devices, NanoMicro Lett. 9 (2017) 1-23, http://dx.doi.org/10.1007/s40820-016-0106-4.

[7] M.C. Petty, C. Michael, Petty-langmuir-blodgett Films - an Introduction, (1996).

[8] R.Y.N. Gengler, A. Veligura, A. Enotiadis, E.K. Diamanti, D. Gournis, C. Józsa, B.J. Van Wees, P. Rudolf, Large-yield preparation of high-electronic-quality graphene by a Langmuir-Schaefer approach, Nano Micro Small 6 (2010) 35-39, http://dx.doi.org/10.1002/smll.200901120.

[9] X.M. Jiang, Z.V. Vardeny, Photoexcitation dynamics in regioregular and regiorandom polythiophene films, Phys. Rev. B 64 (2001) 1-6, http://dx.doi.org/10. 1103/PhysRevB.64.235122.

[10] O. Knopfmacher, M.L. Hammock, A.L. Appleton, G. Schwartz, J. Mei, T. Lei, Highly stable organic polymer field-effect transistor sensor for selective detection in the marine environment, Nat. Commun. 5 (2014) 1-9, http://dx.doi.org/10.1038/ ncomms3954.

[11] A. T.S, D.R.D. T, E.M. Atlanta, Addendum to the toxicological profile for methylene chloride, Agency Toxic Subst. Dis. Regist (2010) 1-17.

[12] N.J.D. H, S. Services, Hazardous Substance Fact Sheet: Tetrahydrofuran, (2004), pp. 1-6.

[13] K.M.M. Möller, Polymer Science : a Comprehensive Reference, first ed., (2012).

[14] U.S.D.O, Transportation, Regulations _ Federal Motor Carrier Safety Administration, (2011), p. 2 20/05/2011.

[15] I. ABTECH Scientific, Advanced Biochip Technologies, Price List, (2017) http:// www.abtechsci.com, Accessed date: 23 January 2017.

[16] B.J. Schwartz, CONJUGATED polymers as molecular materials: how chain conformation and film morphology influence energy transfer and interchain interactions, Annu. Rev. Phys. Chem. 54 (2003) 141-172, http://dx.doi.org/10.1146/ annurev.physchem.54.011002.103811.

[17] A.V. Shevade, M.A. Ryan, M.L. Homer, A.M. Manfreda, H. Zhou, K.S. Manatt, Molecular modeling of polymer composite - analyte interactions in electronic nose sensors, Sensor. Actuator. B 93 (2003) 84-91, http://dx.doi.org/10.1016/S09254005(03)00245-4.

[18] Maria L. Braunger, Priscila Alessio, Leonardo N. Furini, Carlos J.L. Constantino, Clarissa A. Olivati, Influence of the supramolecular arrangement in the electrica conductivity of poly(thiophene) thin films, J. Nanosci. Nanotechnol. 16 (2017) 460-466.

[19] R.C. Sanfelice, V.C. Gonc, C. Av, T. Saocarlense, C.P. Cep, Langmuir, Langmuir Schaefer films of poly(3-hexylthiophene) with gold nanoparticles and gold nanoparticles capped with 1 - octadecanethiol, J. Org. Chem. 118 (2014) 12944-12951.

[20] C.P.L. Rubinger, R.L. Moreira, L.A. Cury, G.N. Fontes, B.R.A. Neves, A. Meneguzzi, C.A. Ferreira, Langmuir-Blodgett and Langmuir-Schaefer films of poly(5-amino-1naphthol) conjugated polymer, Appl. Surf. Sci. 253 (2006) 543-548, http://dx.doi. org/10.1016/j.apsusc.2005.12.096.

[21] R.C. Hiorns, R. De Bettignies, J. Leroy, S. Bailly, M. Firon, C. Sentein, A. Khoukh, H. Preud, C. Dagron-lartigau, High molecular weights, polydispersities, and annealing temperatures in the optimization of bulk-heterojunction photovoltaic cells based on poly(3-hexylthiophene) or poly(3-butylthiophene), Adv. Funct. Mater. 16 (2006) 2263-2273, http://dx.doi.org/10.1002/adfm.200600005.

[22] G. Nagarjuna, M. Baghgar, J.A. Labastide, D.D. Algaier, M.D. Barnes, D. Venkataraman, M. Amherst, N.P. Street, U. States, Tuning aggregation of poly(3-hexylthiophene) within nanoparticles, ACS Nano 6 (2012) 10750-10758.

[23] S. Falke, P. Eravuchira, C. Lienau, Raman spectroscopic identification of fullerene inclusions in polymer/fullerene blends, J. Raman Spectrosc. 42 (2011) 1897-1900, http://dx.doi.org/10.1002/jrs.2966.

[24] J.S. Wilson, J. Kim, P.J. Brown, D.S. Thomas, A. Ko, C.M. Ramsdale, H. Sirringhaus, R.H. Friend, Effect of interchain interactions on the absorption and emission of poly 3-hexylthiophene, Phys. Rev. B 67 (2003) 1-16, http://dx.doi.org/10.1103/ PhysRevB.67.064203.

[25] J.M.W.G. Dicker, T.J. Savenije, B.H. Huisman, D.M. de Leeuw, M.P. de Haas, Photoconductivity enhancement of poly(3-hexiylthiophene) by incresing inter- and intra-chain order, Synth. Met. 137 (2003) 863-864, http://dx.doi.org/10.1016/ S0379-6779(02)01092-5.

[26] C.A. Olivati, M. Ferreira, T. Cazati, T. Balogh, F.E.G. Guimar, O.N.O. Jr., R.M. Faria, Anisotropy in the optical properties of oriented Langmuir - blodgett films of OC 1 OC 6 -PPV, Chem. Phys. Lett. 381 (2003) 404-409, http://dx.doi.org/10.1016/j. cplett.2003.10.010.

[27] R.D. McCullough, R.D. Lowe, M. Jayaraman, D.L. Anderson, Design, synthesis, and control of conducting polymer architectures: structurally homogeneous poly(3-alkylthiophenes), J. Org. Chem. 58 (1993) 904-912, http://dx.doi.org/10.1021/ jo00056a024.

[28] I. Fuks-janczarek, I.V. Kityk, R. Miedzi, E. Gondek, A. Danel, M. Zagorska, Specific features of UV - vis absorption spectra of cis - and trans -polythiophenes, Spectrochim. Acta 64 (2006) 264-271, http://dx.doi.org/10.1016/j.saa.2005.07. 017.

[29] W.C. Tsoi, D.T. James, J.S. Kim, P.G. Nicholson, C.E. Murphy, D.D.C. Bradley, J. Nelson, J. Kim, The nature of in-plane skeleton Raman modes of P3HT and their correlation to the degree of molecular order in P3HT : PCBM blend thin films, ACS Puclications 133 (2011) 9834-9843.

[30] A.R. Aiyar, J. Hong, R. Nambiar, D.M. Collard, E. Reichmanis, Tunable crystallinity in regioregular poly ( 3-hexylthiophene ) thin films and its impact on field effect mobility, Adv. Funct. Mater. 21 (2011) 2652-2659, http://dx.doi.org/10.1002/ adfm.201002729. 
[31] V.A. Online, K. Yuan, L. Chen, Y. Chen, Photovoltaic performance enhancement of P3HT/PCBM solar cells driven by incorporation of conjugated liquid crystalline rodcoil block, J. Mater. Chem. C 2 (2014) 3835-3845, http://dx.doi.org/10.1039/ c4tc00066h.

[32] W. Olthuis, W. Streekstra, P. Bergveld, Theoretical and experimental determination of cell constants of planar-interdigitated electrolyte conductivity sensors, Sensor. Actuator. B 25 (1995) 252-256.

[33] R. Singhal, A. Chaubey, T. Srikhirin, S. Aphiwantrakul, S.S. Pandey, B.D. Malhotra, Immobilization of glucose oxidase onto Langmuir-Blodgett films of poly-3-hexylthiophene, Curr. Appl. Phys. 3 (2003) 275-279, http://dx.doi.org/10.1016/ S1567-1739(02)00215-8.

[34] H. Cheng, W. Lin, F. Wu, H. Cheng, W. Lin, F. Wu, Effects of solvents and vacancies on the electrical hysteresis characteristics in regioregular poly(3-hexylthiophene) organic thin-film transistors, Appl. Phys. Lett. 94 (2009) 1-3, http://dx.doi.org/10. 1063/1.3148332.

[35] X. Ma, G. Li, H. Xu, M. Wang, H. Chen, Preparation of polythiophene composite film by in situ polymerization at room temperature and its gas response studies, Thin Solid Films 515 (515) (2006) 2700-2704, http://dx.doi.org/10.1016/j.tsf.2006.07. 081.

[36] K.C. Persaud, Polymers for chemical sensing, Mater. Today 8 (2005) 38-44.

[37] J.W. Gardner, P.N. Bartlett, K.F.E. Pratt, Modelling of gas-sensitive conducting polymer devices, IEEE Proceedings-Circuits Devices Syst 142 (1995) 321-333, http://dx.doi.org/10.1049/ip-cds:19952170.

[38] E.A. da Silva, V.J.R. de Oliveira, M.L. Braunger, C.J.L. Constantino, C.A. Olivati, Poly(3-octylthiophene )/stearic acid Langmuir and Langmuir-Blodgett films: preparation and characterization, Mater. Res. 17 (2014) 1442-1448, http://dx.doi. org $/ 10.1590 / 1516-1439.288814$.

[39] V.C. Gonçalves, B.M. Nunes, D.T. Balogh, C.A. Olivati, Detection of volatile organic compounds using a polythiophene derivative, Phys. Status Solidi 207 (2010) 1756-1759, http://dx.doi.org/10.1002/pssa.200983723.

[40] L.C. Aifeng Lv, Yong Pan, Gas sensors based on polymer field-effect transistors, Sensors 17 (2017) 1-16, http://dx.doi.org/10.3390/s17010213.

[41] Y. Yang, L. Sun, J. Ou, Y. He, X. Lin, Z. Yuan, W. Lin, W. Hong, D. Yu, Plasmonic effects and the morphology changes on the active material P3HT: PCBM used in polymer solar cells using Raman spectroscopy, J. Raman Spectrosc. 47 (2016) 888-894, http://dx.doi.org/10.1002/jrs. 4917.

[42] M. Baibarac, M. Lapkowski, A. Pron, S. Lefrant, I. Baltog, SERS spectra of poly ( 3 hexylthiophene ) in oxidized and unoxidized states, J. Raman Spectrosc. 29 (1998) 825-832.

[43] J. Yun, J. Peet, N. Cho, G.C. Bazan, S.J. Lee, M. Moskovits, J. Yun, J. Peet, N. Cho, G.C. Bazan, Insight into the Raman shifts and optical absorption changes upon annealing polymer/fullerene solar cells Insight into the Raman shifts and optical absorption changes upon annealing polymer/fullerene solar cells, Appl. Phys. Lett. 92 (2016) 1-3, http://dx.doi.org/10.1063/1.2940205.

[44] J.-S.K. Joseph Razzell Hollis, Quentin Thiburce, Wing Chung Tsoi, Interfacial chemical composition and molecular order in organic photovoltaic blend thin films probed by surface-enhanced Raman spectroscopy, Appl. Mater. Interfaces 8 (2016) 31469-31481, http://dx.doi.org/10.1021/acsami.6b12124.

[45] R. Noriega, J. Rivnay, K. Vandewal, F.P.V. Koch, N. Stingelin, P. Smith, M.F. Toney, A. Salleo, Conjugated polymers, Nat. Mater. 12 (2013) 1-7, http://dx.doi.org/10. 1038/nmat3722.

[46] U. Bhattacharjee, M. Elshobaki, K. Santra, J.M. Bobbitt, S. Chaudhary, E.A. Smith, J.W. Petrich, Characterizing electric field exposed P3HT thin films using polarizedlight spectroscopies, Macromol. Chem. Phys. 217 (2016) 1801-1809, http://dx.doi. org/10.1002/macp.201600113. 